\title{
Firm Information Transparency: Ethical Questions in the Information Age
}

\author{
Antonino Vaccaro, Peter Madsen \\ IN+ Center for Innovation, Technology and Policy Research, IST Lisbon \\ and Carnegie Mellon University, USA, vaccaro@andrew.cmu.edu \\ J. Heinz School of Public Policy and Management and the Center for the \\ Advancement of Applied Ethics, Carnegie Mellon University, USA \\ Peter Madsen <pm2n@andrew.cmu.edu>
}

\begin{abstract}
The wide diffusion of information and communication technologies (ICT) over the last few decades has modified the way in which individuals and institutions interact and conduct social and business activities. We analyze the importance of a firm's information transparency, defined as the degree of completeness of information, regarding their own business activities, provided by each company to the market, and the related role of ICT. First, we present a brief historical perspective of information transparency of business organizations. Then, we analyze the actual role and possibilities offered by ICT to contemporary firms and to society. We develop a model that integrates the ethical and economical/financial forces affecting information transparency applying it to the case study of a famous multinational company. Finally, useful insights for scholars and practitioners are presented.
\end{abstract}

Keywords: Information Ethics, Information Transparency, ICT and Social Change, Business Ethics.

\section{Introduction}

The recurrent scandals in the industrial and financial sectors that have occurred in the last few decades have given rise to ethical concerns and lower esteem in the public's opinion regarding business practices of contemporary firms. As a consequence, consumers around the world continue to ask for more detailed information about business practices and business ethics.

On the other hand, the introduction and diffusion of information communication technologies (ICT) has caused 'the electronic communication effect' [1]. This is the

Please use the following format when citing this chapter:

Vaccaro, A., Madsen, P., 2006, in IFIP International Federation for Information Processing, Volume 223, Social Informatics: An Information Society for All? In Remembrance of Rob Kling, eds. Betleur, J., Numinen, M. I, Impagliazzo, J., (Boston: Springer), pp. 145-156. 
contemporary increase of the amount of information transmitted per unit of time and the reduction of information transmission costs. In particular, the diffusion of webbased technologies can allow corporations to enhance the amount of information concerning their activities transmitted to customers that navigate frequently on the net. As we will see in the following sections, from a conceptual point of view, new virtual technologies could permit the transformation of contemporary firms from opaque to more transparent social institutions. We define a firm's external information transparency as the degree of completeness of information, provided by each company to the market, concerning its business activities ${ }^{1}$ [2]. A transparent company is an institution that shares every kind of information concerning its business activities requested by the society. On the contrary, an opaque company prefers not to disclose any kind of information other than that required by national laws (e.g. financial balance sheets, product information, securities filings, etc.).

The possibilities offered by virtual technologies open new solutions to ethical questions concerning the transparency of contemporary companies. Indeed, if ICT could allow the transmission of any kind of information, it is necessary to understand why today the 'civil' society, and in particular customers, receives only a restricted group of information regarding a firm's activities. This theme is of particular interest today for various reasons. First of all, globalization has spaced out the relationships between customers and companies: every person today purchases goods and services from unknown companies that are located thousands miles away and whose activities are regulated by laws of foreign countries. Secondly, individuals of our multicultural society can be interested to know whether the goods sold by a company are produced without violating their own ethical and religious beliefs. Third, many consumers' associations around the world (e.g. the Italian As.C.I.I., the American Council on Consumer Interest, the Australian Consumers' Association, etc.) have organized and continue to organize protests and boycotts in order to force companies, in particular multinational corporations, to provide detailed information on how they conduct their business. A very well known example is the case of Nike where the company was constrained to disclose detailed information about the location of its factories described by many as 'sweatshops' and their employees working conditions (e.g. average salary, working hours per day, minimum age requested to be hired, etc.).

In the following sections we will try to introduce the new perspectives offered by the diffusion of ICT and transparency concerns. Based upon Kling's vision of ICT as a 'transformative technology"2 [3], we are interested to analyze the main socioeconomical factors that affect the exploitation of ICT by the society and business organizations in relation to the concerns with transparency.

This paper contributes to the literature in several ways. First of all, grounding on Vaccaro's model (2006) of firms' ICT related ethical concerns, it deepens our understanding of the problems of transparency and contextualizes them within the discipline of business ethics. Secondly, it provides an analysis of the new opportunities and perspectives offered by ICT to contemporary business organizations in order to improve their transparency. Finally, it provides normative indications to practitioners and useful insights to scholars for further research.

The remainder of this paper is divided into four sections. The first presents a brief historical perspective of information transparency in business organizations. 
The second contextualizes transparency within the fields of business and information ethics. Section three develops a model that frames the forces affecting the transparency of contemporary firms while the fourth presents a case study analysis and related discussion. Finally, indications for practitioners and insights for further research are proposed.

\section{A Brief Historical Perspective of Firm's Information Transparency}

The human organization we would consider as the first expression of contemporary firms was the artisan workshop. It has represented in the whole globe a common form of business organization for not less than five millennia. It was the most transparent form of business practice in economic history: inside the ancient village everyone knew what was occurring inside the walls of each workshop. Indeed, when ancient villages grew up, a public was born and the public relations of business activities became a reality [4]. Original manuscripts of Medieval and Renaissance periods report artisan laboratories as places opened to the visits of the public $[5,6]$. Business processes were consequently transparent to everyone inside the community. Individuals that tried to hide their knowledge regarding their working practices were accused of wizardry, imprisoned and/or burned in the village square [7].

The first industrial revolution caused the diffusion of immense business organizations with the concentration of many large groups of workers inside the perimeter of productive plants. This major change in the organization of labor and the raise of competition caused a deep transformation of the relationships between new industrial firms and the world: the factory's walls created a division between society and business organizations [8]. Only workers were allowed to enter into the interior areas of productive plants and consequently the information related to business activities were not directly observable by other member of the society. Historians report to us that for a long period the worst social injustices (e.g. exploitation of children work, inhuman working conditions) were committed and remained hidden within the perimeters of factories [9].

After the first industrial revolution, national governments and intergovernmental associations across national borders tried to improve workers conditions inside business organizations through the creations of specific laws that imposed adequate workplace conditions.

On the other hand, a great part of the information regarding firms' activities continued not to be available for the general citizenry. The legislations of developed countries regulated information regarding business activities and limited how much information could be shared with society. Most of these data are disclosed by firms to the society through balance sheets and through product information instructions and manuals added to the purchased goods. As a consequence, since the early $1970 \mathrm{~s}$ individuals and citizen organizations have protested against practices of companies that they thought to be unethical. Consumers demonstrated their desire to receive more and more detailed information regarding how companies conduct their business 
activities and generate their profits. The dawn of the era of 'consumer rights' had occurred.

\section{From Traditional to Virtual Transparency Tools: New Perspectives for Contemporary Firms}

In the 20th Century, before the advent of the new virtual technologies, the relationship between the firm and the social system was conducted through products and/or services supplied by the firm, direct contacts between customers, suppliers and the firm's workforce, marketing and communication initiatives, and official documents such as balance sheets and financial reports [2]. The diffusion of ICT, and in particular of Internet-based technologies, has, however, modified the interactions between business organizations and the socio-economical environment. Firms started to look at websites as an opportunity to interact with current customers or potential ones. Indeed, today, a growing number of individuals can easily connect to the Net, reach directly the website of a company, read the available information provided on the electronic pages and eventually contact the firms' employees through their email server. This part of the market that frequently uses the Internet and other ICT-based solutions is a very important target of contemporary corporations due to its high financial possibilities and related purchase capabilities.

Consequently Internet based technologies have represented an important driver of change because they lead to firms choosing what kind of information should and should not be available on their websites. In theory, new virtual technologies may allow firms to become completely transparent institutions or naked corporations [10]. Indeed, introducing web-cams and microphones in every room of a firm's building, and connecting these systems on a website, could allow monitoring in real time of every workplace activity, conversation or decision taken inside the firm.

In the real world, a large number of companies have not adopted new virtual technologies to transform themselves into completely transparent institutions. In contrast with the rising requests of more transparency provided by individuals and consumers' associations, such as the Nike case, contemporary companies share only a limited set of information regarding their business activities.

We are interested in considering not only the ethical, but also other social and economic components that affect the transparency of contemporary firms. Indeed, the contextual inquires [11] that this work will attempt to raise and answer are: what are the social, cultural and environmental conditions that affect the ICT-enabled information transparency of contemporary firms? What are the expected results of higher levels of ICT-enabled transparency of business organizations on society?

We will try to answer such research questions following a four-step conceptual path. First, based upon recent economic and managerial theories of the firm $[12,13]$, we will identify the economic and financial forces affecting firms' information transparency. In a second step, we will introduce the ethical forces following the indication of Vaccaro's model [2]. As a result, we will present a new framework of the forces that affect firms' information transparency as represented in Figure 1. In 
the following section we will analyze a case study useful in testing the new model followed by a discussion and some conclusions.

\section{Virtual Transparency: Perspectives and Constrains}

This section introduces and analyzes the economic/financial and ethical factors affecting the transparency of contemporary firms. This analysis will result in a fivepart model presented later.

\subsection{Transparency from an Economic and Financial Perspective}

The appropriate identification of the economic and financial forces affecting a firms' information transparency should require the definition and contextualization of the firm's specific role inside the economic system and more generally within the society. Among theories that conceptualize business organization in this regard are those that focus upon transaction costs $[12,14]$, agency theory $[13,15]$, measurement costs [16], incomplete contracts [17] and knowledge-based resources [18].

We propose a vision of the firm as a natural response of the society to market failures: when a market is not able to provide products and/or services requested by the society, the foundation of a firm represents a solution to supply this need [12]. Firms are created to reduce market transaction costs [12], to exploit economies of scale and scope, to aggregate different and heterogeneous knowledge based resources [18], with the final objective to provide a product and/or a service to society. Moreover, competition guarantees the proliferation of more effective and efficient economic actors while private investors provide the necessary financial support.

Following this perspective three different and contrasting forces affect information transparency of contemporary business organization. The first force is represented by the requests of customers that, as already stated, demand higher levels of information transparency. The second force is represented by the pressure of existent and possible competitors that, in order to improve their market position and power, try to acquire and exploit every useful piece of information from other firms. The third force is represented by the pressure of investors who might choose to modify their financial support to firms' activities reducing both the value of shares and more in general the whole financial capability of the company, if their demands for a more transparent firm are not met.

These three different forces allow us to understand how an 'optimal level' of information transparency could be decided by firms in relation to economic and financial pressures. In order to simplify our analysis, we consider, as a preliminary step, an ideal company that, given specific market conditions and similar productive/technological capabilities available for all competitors, is able to provide optimal service to society and to maximize investors' returns. 


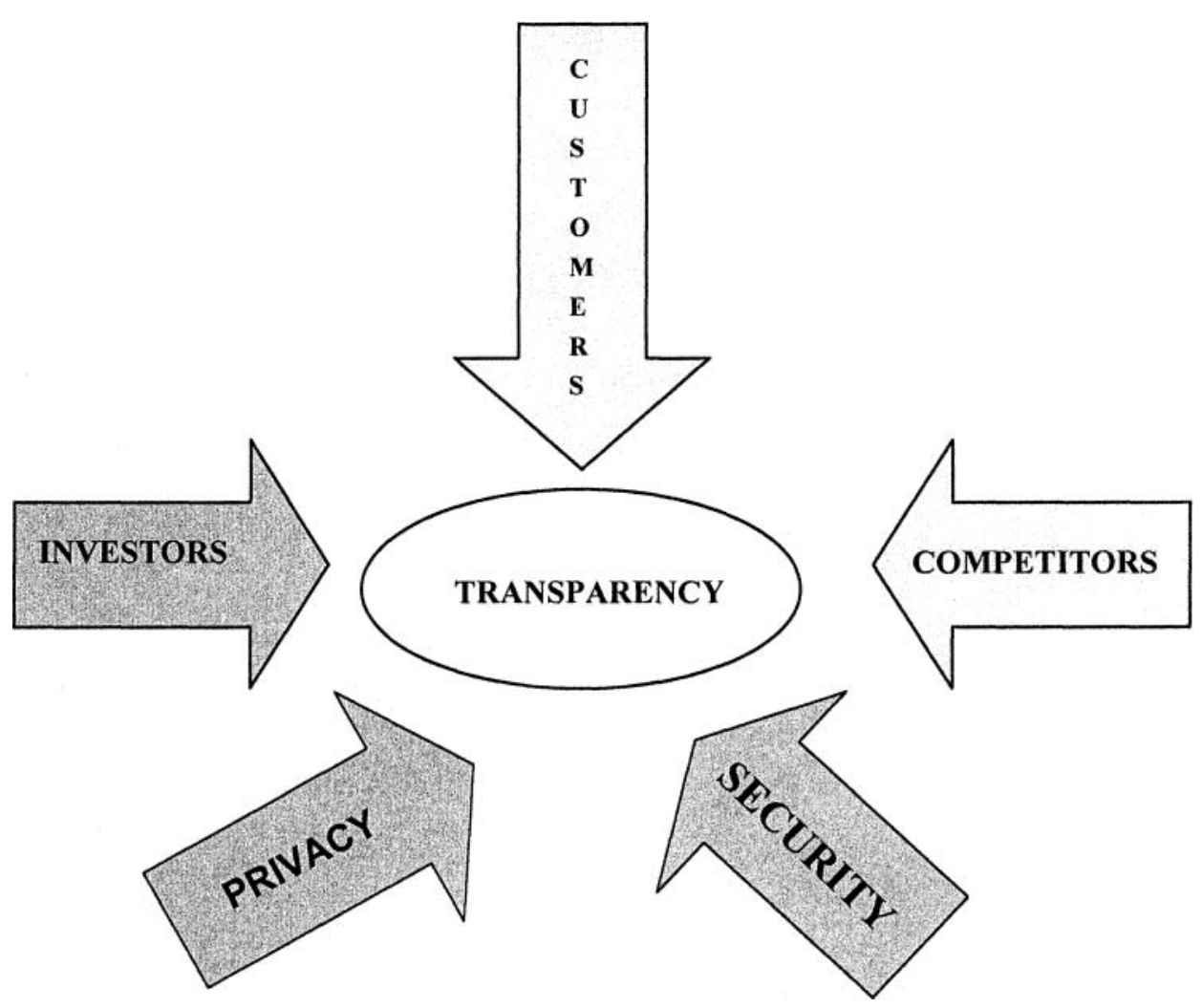

Figure 1: The five forces affecting a firm's information transparency

If we imagine that the second and the third force do not affect the market in which this firm operates, i.e. there is no pressure from existent and possible competitors and none from investors, we should expect a high level of information transparency in our hypothetical firm. Indeed, given two similar products, a customer will choose those provided by a company whose activities are shared with the society instead of those sold by an opaque institution [2]. Consequently, given the absence of the second and third force, every company will try to disclose the highest amount of information in order to maintain the preference of its customers and to gain those of potential ones.

In an opposite situation we could have a market condition in which customers and investors are not interested in a firms' information transparency and each piece of information shared by the firm can be successfully exploited by competitors to improve their comparative position. In this second hypothetical situation, every firm 
would obviously choose not to share any kind of information because doing so might risk the loss of market position.

Finally, in the case of a market in which there is only the third force, a company will provide a transparency level sufficient to allow investors to control what kind of institution they are financially supporting. The disclosure of a company's information will be in fact associated with the objective to maintain current investors and to attract new ones.

In the real world, companies have to face more complex business conditions. First of all, every company is not sure its service is economically optimal for society because it does not know exactly how effective the operations of other competitors are. This problem is complicated by the fact that different ethical and cultural beliefs can turn on different concepts of 'economical optimality.'

Secondly, firms exploit every kind of useful information of their competitors to improve their market position. An extreme example is reverse engineering in which firms dismantle competitors' products to acquire useful technological information. Consequently, contemporary firms limit the spread of their business data due to the competitors' threat. Finally, there are possible conflicts of interests between customers and investors. The maximization of investors' profits could be in partial conflict with customers' benefits. For example higher levels of product's quality controls can represent a benefit for customers but a decrease of the revenues for investors due to the raise of control costs. The disclosure of information related to quality controls could cause contrasting reaction of customers and investors interested to pursue opposite objectives. Consequently, firms can choose to limit the spread of those pieces of information that can cause incompatible requests of customers and investors.

\subsection{The Ethical Concerns}

A firm's transparency is conditioned not only by the financial and economical forces that impinge upon it, but also by ethical pressures. Using Vaccaro's model [2], we divided such forces in two main categories, namely, privacy and security. Privacy and security have to do with both individuals that are part of the firm's organization as well as other individuals external to the firm such as customer and suppliers.

Privacy represents an important ethical concern of the Internet era. Indeed, of all the ethical issues associated with the use of ICT, perhaps none has received more media attention [19]. Firm transparency can be affected by privacy requests of employees, customers and suppliers. While ICT can today lead to a complete transparency level for a business organization, this technical possibility cannot be achieved due to the privacy rights of employees. The literature in business ethics and in sociology has widely described the increasing number of privacy rights of employees due to the pressure caused by new ICT [20, 21]. Employees in fact make a claim of privacy principles related to a wide set of information such as salary, medical condition, personal information, working hours, etc. Analogously, customers and suppliers can expect that part of their contractual agreements and activities contracted in with a company will not be made public-ally available and remain a private matter. 
Since $9 / 11$, the security concerns of individuals and social institutions have increased greatly around the world. As a consequence, economic and social interactions in the current business environment need to be carefully managed in order to guarantee adequate security to all agents involved in a firms' activities. While customers around the world demand higher levels of firm transparency, it could be claimed that higher levels of transparency could allow other individuals to commit fraudulent or dangerous actions. For example, a nuclear electric-generating facility which has shared detailed information about its productive plants could be attacked easily by terrorists attempting to cause a nuclear disaster. Analogously, unscrupulous parties could exploit detailed personal information of employees that has been shared by a firm for illegal and/or dangerous purposes.

\section{Case Study Analysis}

The development of the five-part model in the previous section has showed that a level of complete transparency does not a priori represent a reasonable choice of contemporary business organizations. Indeed, we demonstrated that companies have to limit the amount of information related to their business activities available in the market in order to defend their competitive position, to manage adequately the relationships with investors, to respect the privacy rights of customers and suppliers and to guarantee the security of individuals and the general public. On the other hand, the continuous demands of customers and the new opportunities offered by ICT suggest that higher levels of information transparency are desirable. We present in this section the case of the Artsana group, a big multi-national company whose transparency level has been changed exploiting the opportunities offered by the Internet-related technologies.

\subsection{The Artsana Group}

Artsana is a multinational company founded in the 1946 by Piero Catelli in Como, Italy. It currently has a workforce of more than 7000 employees and a worldwide presence in two main market sectors: products for children and for hospitals. In the last decade, this firm has exploited opportunities offered by Internet-based technologies so as to improve the relationship with people throughout the world through a major increase in its level of transparency.

Before the 1990s, communications between Artsana and society were limited. Indeed, the company provided only the mandatory product information in the instructions that were added in a products' pockets. The organization's balance sheet was also a mandatory document, which presented synthetic descriptions of the company's activities and shared outside the firm's internal environment. Today, the group has 26 websites with more than 10.000 web pages that allow users to electronically access detailed information about its products and business practices.

The interviews conducted with one of the top managers of the group confirmed that the transparency of this company is mainly produced by two forces, namely, privacy and customers. Indeed, the investors' force is represented by the three of 
Piero Catelli's sons who work inside the company as managers in the General Direction $^{3}$. In other words, investors are not concerned about transparency because all of the information that they need is already available thanks to their position in the Artsana organization. Moreover, transparency is not affected by competitors because product and process technologies relevant for the business activities are protected by patents and, as confirmed by a manager of the organization, there are no "secrets other than working hard every day" (Interview, 2006). Finally, Artsana does not manage activities nor does it own any productive plants that can be exploited to endanger individuals or disrupt social security by terrorists. Consequently, the two driving forces that 'shape' Artsana's transparency policy are privacy and customers' demands.

Customers placed strong pressure on Artsana to produce a high level of transparency. During the 1990s numerous companies located in Asia, suppliers of European firms specializing in the commercialization of toys were accused of exploiting children in their productive activities under inhumane working condition. In 1993, various newspapers reported fire of an Asian toys producer's plant, in which 87 employees died and more than 47 were severely hurt due to the lack of an adequate security system. In the following years, various editorials available on the web and letters written by global activists for the respect of human rights accused important multinational companies, an in particular Artsana, to be client of this toy factory and consequently to nourish unethical business activities.

After this tragic event, Artsana decided not only to modify its business activities through the development and following of a rigid code of business ethics and the application of an ethical certification systems for its suppliers (i.e. SA8000 standards), but also it decided to raise its transparency level. The respecting human dignity and social justice and acting with integrity have been an imperative both of the founder and of whole company's workforce ${ }^{4}$. Consequently, more transparency of business practices was established as a good strategy to improve trust and build better relationships with customers, in particular and with society in general.

Since the 1995, the company started to progressively disclose extensive documentations of its products and business activities. The website of the group provides the code of ethics approved by the company's board in 1998, financial reports and also, information regarding the location of plant facilities, working conditions of employees and sub-contractors, etc. ${ }^{5}$ Moreover, the company has recently created a specific office that is responsible to answer the questions of customers, and/or potential ones, regarding its products and business practices. Emails and phone-calls directed to the call center located at the group headquarters are the main ways to interact directly with the company. Moreover, it is possible to subscribe to a mailing list in order to receive a monthly email with all the relevant news of the corporation.

Privacy is a value that matters much in such a process of information disclosure. Indeed, the data posted on the group websites have to obey the national privacy laws and in many cases information is provided in aggregated form in order to avoid identification concerns. For example, the Chicco ${ }^{6}$ portal supports a newsletter that allows new parents and parents-to-be to exchange information but to do so anonymously without providing any personal information about members and 
contributors. Analogously, the personal information of customer service employees is protected through email accounts that do not cite their names and surnames.

\subsection{Discussion}

The Artsana case has offered an interesting example to test the indications of our five-part model and to analyze the opportunities offered by ICT in order to improve the relationship between firms and society. In relation to the firms' transparency concern, this case study suggests that there are two main contributions offered by virtual technologies to our society.

First of all, the Internet has supported the creation of social movements of 'global citizens' that actively apply strong pressures upon companies in order to assure humane working conditions and to promote the following of fundamental sound ethical principles. The websites of these organizations and emails allow the spread of information and personal opinions regarding events occurring around the world today. Contemporary companies consequently have to interact with a networked society that is not only more heterogeneous, but also more informed and active against business institutions that operate unethically.

The case of Artsana shows also that Internet-based technologies can effectively support firms to improve their transparency level. Before the 1995, Artsana was an 'opaque' corporation that provided only the information necessary to respect national laws. The scandals that occurred in Asia forced this company to raise its transparency level in order to gain trust with customers and potential ones. Indeed, Artsana's top management recognized the disclosure of information related to the company's products and activities as a strategy to improve the image of the company in the global market. The creation of different websites has allowed Artsana to provide detailed information related to its business while the email supported direct contacts with individuals interested in receiving specific information.

The progressive increase of this company's transparency was enabled by a set of favorable conditions illustrated by our five-part model. The lack of potential security threats, the share ownership concentrated in the Catelli family and the absence of 'company secrets' to protect, have allowed this firm to disclose large volumes of information to society through the successful use of virtual technologies. As already mentioned, customers have represented the driving force behind Artsana's transparency while privacy concerns have limited the disclosure of personal information.

\section{Conclusion}

In this paper we have introduced and analyzed concerns associated with the information transparency of contemporary business organizations and the related role of ICT. The development of a five-part model and the analysis of a case study has shown that, while there are ethical and financial/economical forces limiting the spread of information, customers' pressure and the new opportunities offered by the diffusion of ICT can enable higher levels of information transparency in 
contemporary firms. Information transparency can be exploited in fact by corporations as an opportunity to improve trust and confidence of existent customers and to attract new ones. Our results confirm Kling's analysis of organizations as 'open systems' [22], i.e. institutions whose behavior is influenced by the relationship that is established with society and its individual members. In this context, ICT play a doubly important role. They widen the horizon of interaction of each firm with the global society allowing contact with distant customers and 'global citizens' to take place. But also, they create the possibility of a networked society in which ethical concerns are shared and promoted as a spontaneous social ethical need. In other words, ICT is transforming society and as a result, a progressive and radical social change can be expected in the future that will see the creation of more transparent markets and more transparent firms in which customers will have more detailed information of a firms' business practices and in which higher levels of interactions will be possible between business organizations and the public.

\section{Acknowledgements}

One of the authors is grateful to João César das Neves and to Andrea Adamo for the generous support and suggestions they provided during the development of this paper.

\section{References}

1. T. Malone, J. Yates, R. Benjamin, Electronic Markets and electronic hierarchies, Communication of the ACM, 30 (6), 484-497 (1987).

2. A. Vaccaro, Privacy, Security and Transparency: ICT-related ethical perspectives and contrasts in contemporary firms, in: Social Inclusion: Societal and Organizational Implications for Information Systems, edited by D. Howcroft, E. Trauth, J. I. DeGross, (Springer, New York, forthcoming 2006).

3. R. Kling, Computeration and Social Transformation, Science, Technology, \& Human Values 16 (3), 342-367 (1991).

4. N.S. Gras, Shifts in Public Relations, Bulletin of the Business Historical Society, 19(4), 97-148 (1945).

5. B. De Dominici, Vita de Pittori, Scultori e Architetti Napoletani (Napoli, 1742).

6. T. Garzoni, La piazza universale di tutte le professioni del mondo (Venetia, 1589).

7. J. Fo, S. Tomat, L. Malucelli, Il libro nero del cristianesimo, (Nuovi Mondi Media, Bologna, 2006)

8. P. Deane, The First Industrial Revolution (Cambridge University Press, Cambridge, 1979).

9. C. Tuttle, Hard At Work in Factories and Mines: The Economics of Child Labor During the British Industrial Revolution, International labor and working class history 59, 142145 (2002).

10. D. Tapscott, D. Ricoll, The Naked Corporation (Free Press, New York, 2003). 
11. R. Kling, What Is Social Informatics and Why Does It Matter?, D-Lib Magazine, 5(1), 1999.

12. R.H. Coase, The Nature of the Firm, Economica 4, 386-405 (1937).

13. B. Holmström, and P. Milgrom, Multitask Principal-Agent Analyses: Incentive Contracts, Asset Ownership, and Job Design, Journal of Law, Economics, and Organization 7, 24$52(1991)$.

14. O. E. Williamson, The Mechanisms of Governance (Oxford University Press, Oxford, 1986).

15. B. Holmström, Moral Hazard in Teams, The Bell Journal of Economics, 13, 324-340, (1982)

16. Y. Barzel, Economic Analysis of Property Rights (Cambridge University Press, Cambridge, 1989).

17. O. Hart, Firms, Contracts and Financial Structure (Oxford University Press, Oxford, 1995).

18. C.K. Prahalad, G. Hamel, The Core Competence of the Corporation, Harvard Business Review, 6 (May-June), 79-91 (1990).

19. H.T. Tavani, Ethics and Technology, Ethical Issues in an Age of Information and Communication Technology (John Wiley \& Soons, Inc., Hoboken, 2004)

20. G.T. Marx, Let's Eavesdrop On Managers, Computerworld 26(16), 29 (1992).

21. G. T. Marx, and S. Sherizen, Monitoring on the job: how to protect Privacy as well as Property, Technology Review, 89 (Nov-Dec), 63-72 (1986).

22. R. Kling, and T. Jewett, The Social Design of Worklife With Computers and Networks: An Open Natural Systems Perspective, Advances in Computers 39, 239-293 (1994).

I In the following part of the paper we will refer to it simply as 'transparency,' or 'firms' transparency' or 'external transparency' bearing in mind that we are not interested in analyzing in this work the 'internal transparency' that is the degree of virtual connectivity (i.e. availability of access through ICT tools) between the workforce and the external environment [2]

2 A transformative technology is one that can be exploited by individuals and organizations in order to modify and resolve current problems of society.

3 In particular, Michele is C.E.O. of the group, Enrico is Account Director, and Francesca is Marketing and Communication Director.

4 This fact is confirmed by the current financial involvement of Artsana in numerous humanitarian initiatives around the world and by the awards received by Piero Catelli for the ethical excellence of his career as entrepreneur. In particular, the President of the Italian Republic appointed him Cavaliere del Lavoro, the most prestigious award provided by the Italian government to entrepreneurs. Moreover, while there are various websites that declare Artsana did not provide any compensation to the families of the victims and to the injured employees of the China factory, an official report of Assogiocattoli, the Italian not-for-profit organization of Italian toys producers, assures that Artsana has created a compensation fund and entrusted Caritas Hong Kong to be responsible for the distribution of the money to the victims.

5 Gruppo Artsana, Company Profile, Human Resources, http://www.artsana.com/eng/html/company/i_company.htm (May 1st, 2006)

6 Chicco is one of the most known and successful brands of the Artsana group. 